Research Article

\title{
Prevalence and Antibiotic Resistance Pattern of Salmonella Isolated from Caecal Contents of Exotic Chicken in Debre Zeit and Modjo, Ethiopia
}

\author{
Destaw Asfaw Ali ${ }^{D},{ }^{1}$ Belege Tadesse, ${ }^{2}$ and Aragaw Ebabu ${ }^{3}$ \\ ${ }^{1}$ College of Veterinary Medicine and Animal Science, University of Gondar, Gondar, Ethiopia \\ ${ }^{2}$ School of Veterinary Medicine, Wollo University, Dessie, Ethiopia \\ ${ }^{3}$ College of Veterinary Medicine and Agriculture, Addis Ababa University, Addis Ababa, Ethiopia
}

Correspondence should be addressed to Destaw Asfaw Ali; asfawdestaw@gmail.com

Received 5 July 2019; Revised 14 December 2019; Accepted 3 January 2020; Published 25 January 2020

Academic Editor: Giuseppe Comi

Copyright (c) 2020 Destaw Asfaw Ali et al. This is an open access article distributed under the Creative Commons Attribution License, which permits unrestricted use, distribution, and reproduction in any medium, provided the original work is properly cited.

\begin{abstract}
A cross-sectional study was conducted between December, 2013, and May, 2014, to determine the prevalence and antibiotic resistance feature of Salmonella isolated from broilers slaughtered in Debre Zeit and Modjo towns, Ethiopia. A total of 384 caecal content samples were collected for microbiological examination following the standard techniques and procedures outlined by the International Organization for Standardization to isolate Salmonella. The sensitivity of the isolates subjected to nine antimicrobials was tested by the Kirby-Bauer disk diffusion method. The overall prevalence of Salmonella was 14.6\%, and its occurrence differ significantly by farm $(p<0.05)$. The occurrence of the bacteria was not statistically different in the midland $(15.2 \%)$ and lowland (13.3\%) $(p>0.05)$ and between males (13.5\%) and females (15.6) $(p>0.05)$. Of the 50 isolates, 48 were resistant to at least one drug. Multidrug resistance was recorded in $43(86.0 \%)$ of the isolates. The study demonstrated considerable prevalence and high antimicrobial resistant Salmonella in exotic chicken and indicates the potential importance of chickens as source of foodborne salmonellosis and multiple antimicrobial resistance of Salmonella. Improving the hygienic practice of farms could help to reduce the occurrence of Salmonella in farms. Further studies are needed to describe the risk factors associated with the emergence of drug-resistant Salmonella in chicken.
\end{abstract}

\section{Introduction}

Despite global improvements in public health facilities, bacterial infections still remain an important public health problem worldwide. Salmonellosis is one of the main foodborne zoonotic and animal husbandry problem throughout the world $[1,2]$. The bacteria cause foodborne poisoning in humans, mainly through animal products that include poultry, cattle, and pig products $[3,4]$.

Salmonella is facultative anaerobic Gram-negative rod that grows optimally at $35^{\circ} \mathrm{C}$ to $37^{\circ} \mathrm{C}$ and catabolizes a variety of carbohydrates into acid and gas in addition to $\mathrm{H}_{2} \mathrm{~S}$ gas production [5]. The genus comprises two species: Salmonella enterica and Salmonella bongori [6].
Salmonellosis has been recognized in all countries but seems to be most prevalent in areas of intensive animal husbandry, especially poultry and swine production. Although primarily an intestinal bacteria, Salmonella is widespread in the environment and commonly found in farm effluents, human sewage, and in any material subject to fecal contamination [7]. The natural habitat of Salmonella may be divided into three categories: (i) highly adapted to men and agents of typhoid fever; (ii) highly adapted to animals responsible for animal paratyphoid; and (iii) most of the serovars that affect men and animals [8].

In developing countries, domestic chickens live in close contact with humans in both urban and village communities, often being housed overnight in the family home [9]. 
Infection of the chicken leads to fecal shedding into the environment. Contamination of meat and eggs is the main chain of human Salmonella infections in addition to the contact of workers in poultry farms and slaughtering houses [10]. The risk development of antibiotic resistance in human and animal is one of the main reasons for control in animals [11].

Antimicrobial resistance is a global public health problem $[12,13]$. Resistance to antimicrobials could be due to three basic mechanisms: (i) modification of the antibiotic by decreasing absorption or increasing efflux of the antibiotic by using their enzymes; (ii) change in the target site of the antibiotic; and (iii) acquisition of the ability to break or modify the antibiotic [14]. Several lines of evidence demonstrate that the use of antimicrobial agents in food animals contributes to the emergence and dissemination of antimicrobial resistance in food borne Salmonella [15]. In recent years, antimicrobial resistance is a serious problem in the treatment of Salmonella infection [16, 17].

Salmonella infections of food animals play an important role in public health and particularly in food safety, as food products of animal origin are considered to be the major source of human Salmonella infections [18]. Cross-contamination during food processing is also monitored as contamination by healthy food handlers. In recent years, it is reported that livestock and their products can contribute to as much as $96 \%$ [19] of the total Salmonella infection in humans [20].

In Ethiopia, several factors including under and malnutrition, HIV-AIDS, the unhygienic living circumstances, and the close relations between humans and animals may substantially contribute to the occurrence of salmonellosis. Although surveillance and monitoring systems are not in place and its epidemiology is not described, qualitative and quantitative syntheses of previous studies could shed light on the occurrence of the disease and the major serotypes that frequently cause infections. In a recent study on diarrheal patients, the prevalence of the disease was estimated at 8.22\% [21], and in patients with febrile illnesses, typhoid fever was recorded in $5.85 \%$ of the patients with a higher occurrence in children aged 3 to 14 years (6.6\%) compared with children aged 15 to 17 years (1.1\%) [22]. These reports imply the need for a policy to promote public hygiene and regularly screen individuals in contact with food items for public consumption.

Despite salmonellosis imposes a significant cost to societies, in many countries, few countries report the data on economic cost of the disease $[11,23]$. The disease offers one of the greatest scopes for research particularly when relating to developing countries [24]. Although studies conducted in Ethiopia indicated the considerable importance of Salmonella in animals and humans $[25,26]$, studies on chicken are limited. Therefore, this study was undertaken with the objective to determine the prevalence and antibiotic resistance features of Salmonella isolated from the caecal contents of broilers.

\section{Materials and Methods}

2.1. Study Areas. The study was conducted in Debre Zeit and at Modjo, Ethiopia. Debre Zeit and Modjo are found in
Oromia regional state 47 and $72 \mathrm{~km}$ South East of Addis Ababa, respectively. Debre Zeit is located at $9^{\circ} \mathrm{N}$ and $39^{\circ} \mathrm{E}$, at an altitude of about $1900 \mathrm{~m}$ above sea level. Modjo is located at $8.3^{\circ} \mathrm{N}$ and $39^{\circ} \mathrm{E}$, at an altitude of $1774 \mathrm{~m}$ above sea level. The areas experience a bimodal rainfall with the main rainy season extending from June to September. Debre Zeit and Modjo have annual average rain fall of $800 \mathrm{~mm}$ and $776 \mathrm{~mm}$, average temperature of $18.7^{\circ} \mathrm{C}$ and $19.4^{\circ} \mathrm{C}$, and mean relative humidity of $61.3 \%$ and $59.9 \%$, respectively [27].

2.2. Study Design. The study was cross-sectional and conducted from December 2013 to May 2014. The animals were apparently healthy chicken slaughtered at commercial processing plants and private producers. The chickens were rose breed maintained under intensive management system and are of the same age (45-50 days) groups. The sample size was determined according to Thrusfield [28] with an expected prevalence of 50\%, 95\% confidence interval, and 5\% absolute precision. Accordingly, a total of 384 chickens were sampled: 133 from Alema Farms commercial processing plant, 120 from Modjo poultry slaughtering house, and 131 from three other private holders in Debre Zeit. Sampling was systematic and random. The caecum of each chicken was punctured with sterile scalpel, and about 5 grams of caecal contents were collected in labeled universal bottles. Samples were transported to the Microbiology laboratory of the Collage of Veterinary Medicine and Agriculture, Addis Ababa University, by using an ice box. The sample was refrigerated at $4^{\circ} \mathrm{C}$ and processed within 24 hours.

2.3. Isolation and Identification. The isolation and identification of Salmonella was according to the techniques recommended by the International Organizations for Standardization (ISO-6579) [29] with Global Salmonella Survey (GSS) and WHO guidelines [30]. All the media used were prepared according to the instructions of the manufacturer.

\subsubsection{Culture Methods}

(1) Nonselective Preenrichment. The refrigerated samples were thawed at room temperature, and 5 grams of the caecal contents were preenriched with $45 \mathrm{ml}$ of buffered peptone water at a ratio of 1:9 BPW (HiMedia M1494, Mubi, India). The suspension was harmonized by mixing using a vortex and incubated for $24 \mathrm{hr}$ at $37^{\circ} \mathrm{C}$.

(2) Selective Enrichment. A portion $(1 \mathrm{ml})$ of the preenriched cultured was transferred to $10 \mathrm{ml}$ of selenite-F (Titan TM389, Biotech, India) broth, and another $0.1 \mathrm{ml}$ portion was transferred to $10 \mathrm{ml}$ of RV broth (HiMedia M880, Mubi, India) and incubated at $37^{\circ} \mathrm{C}$ and $42^{\circ} \mathrm{C}$ for 24 hours, respectively.

(3) Plating Out and Identification. From each selective enrichment broth media (RV and SF), a loop full of the suspension was inoculated on to xylose lysine deoxycholate 
(XLD) (HiMedia M031, Mubi, India) and Brilliant Green (BG) (Titan TM951, Biotech, India) agars and incubated at $37^{\circ} \mathrm{C}$ for $24 \mathrm{hr}$. The incubation was prolonged to $48 \mathrm{hr}$ for those who did not show any growth during the $24 \mathrm{hr}$ incubation. Typical colonies, having a slightly transparent zone of reddish color and a black center (XLD), and atypical lactose-positive salmonellae, yellow with or without blackening, from XLD and BG plate agars were isolated and subcultured on nutrient agar (Oxoid CM0003, Basingstoke, England).

2.3.2. Biochemical Tests. Biochemical tests were performed by using the following tests: triple sugar iron agar (TSI) (Oxoid CM0277, Basingstoke, England), lysine iron agar (LIA) (Oxoid CM381, Basingstoke, England), urea broth (Oxoid CM53, Basingstoke, England), Voges Proskauer (VP) (Himedia M070I, Mumbai, India), tryptone broth (Himedia M463, Mumbai, India) for indole test.

2.3.3. Antimicrobial Tests. The susceptibilities of the isolates to antimicrobials were tested by using the Kirby-Bauer disk diffusion method. The isolates were tested for the following antibiotics: ampicillin (AMP) $(10 \mu \mathrm{g} / \mathrm{ml})$, streptomycin (STR) $(10 \mu \mathrm{g} / \mathrm{ml})$, kanamycin (KAN) $(30 \mu \mathrm{g} / \mathrm{ml})$, ceftriaxone (CRO) $(30 \mu \mathrm{g} / \mathrm{ml})$, chloramphenicol (CHL) $(30 \mu \mathrm{g} / \mathrm{ml})$, oxytetracycline (OXT) $(30 \mu \mathrm{g} / \mathrm{ml})$, sulfamethoxazole-trimethoprim (SXT) $(25 \mu \mathrm{g} / \mathrm{ml})$, nalidixic acid (NAL) $(30 \mu \mathrm{g} /$ $\mathrm{ml})$, and amoxicillin (AMC) $(30 \mu \mathrm{g} / \mathrm{ml})$, all from Oxoid, England. The isolates were inoculated to brain heart infusion broth (Oxoid CM0225, Basingstoke, England) and incubated for 8 hours at $37^{\circ} \mathrm{C}$ till the turbidity of the suspension equals to that of a $0.5 \mathrm{McF}$ arland standard. Plates of Mueller Hinton agar (Oxoid CM0337 Basingstoke, England) were seeded with socked inoculum of sterilized cotton swabs. Antimicrobial discs were placed on the agar surface at about $2 \mathrm{~cm}$ apart. The plates were incubated at $37^{\circ} \mathrm{C}$ for $24 \mathrm{hr}$, and the diameter of the zones of inhibition was measured by using a caliper. The measurements were compared with zone size interpretative chart furnished by Clinical Laboratory and Standard Institute document M100-S23 (M02-A11) [31], and zones were graded as susceptible, intermediate resistance, and resistant.

2.4. Statistical Analysis. The data were entered into a Microsoft Excel 2007 and imported to SPSS version 20 for analysis. Descriptive statistics was used to describe the data. Pearson's chi-square $\left(\chi^{2}\right)$ test was used to test associations. Alpha was set at 0.05 .

\section{Results}

3.1. Prevalence of Salmonella. Salmonella was recovered in $56(14.6 \%)$ of the samples. The bacteria were isolated in 28 (21.1\%), $16(12.2 \%)$, and $12(10.0 \%)$ of the samples that originated from Alema, Aleka Amba, and Modjo farms, respectively (Table 1). The occurrence of the bacteria differed significantly by farm $(p<0.05)$. Its occurrence was higher at
Alema farms but not significantly different between Aleka Amba and Modjo farms $\left(\chi^{2}=0.31 ; p=0.578\right)$. The occurrence of Salmonella did not differ by altitude $(p>0.05)$ and sex $(p>0.05)$ (Table 2).

\subsection{Antibiotic Resistance}

3.2.1. Mono Drug Resistance. The antimicrobial susceptibility features of the isolates are given in Table 3 . The highest resistance was recorded for oxytetracycline (82.0\%) followed by ampicillin (70.0\%). Resistance to kanamycin and ceftriaxone were observed in $26.0 \%$ and $6.0 \%$ of the isolates, respectively. Intermediate resistance to each of the tested drugs was recorded in four or more of the tested isolates. Only two isolates were sensitive to all drugs, and five were resistant to a single drug.

3.2.2. Multidrug Resistance. The multidrug resistance features of the isolates are shown in Table 4. Of the tested isolates, $43(86.0 \%)$ were resistant to two or more (up to seven) antimicrobials and 26 multidrug resistance profiles were observed. The number of isolates resistant to five drugs was higher followed by two drug-resistant isolates. The OXT, AMP, CHL, NAL, SXT, and STR (4/43) phenotype occurred more frequently followed by the OXT, AMP, CHL, NAL, SXT, and KAN (3/43) phenotype.

\section{Discussion}

The overall prevalence of Salmonella was $14.6 \%$ and differed by location. The prevalence difference in these sites could be due to differences in environmental contamination or management systems. However, the prevalence difference between Aleka Amba and Modjo farms did not differ statistically $(p>0.05)$. The prevalence difference of isolates between midland and lowland was $15.2 \%$ and $13.3 \%$, respectively, while that of sex was $15.6 \%$ in female and $13.5 \%$ in male who did not also differ statistically $(p>0.05)$, and hence, there was no association between these risk factors and the prevalence of the pathogen.

The overall prevalence of Salmonella was $14.6 \%$. The result is in agreement with the $16.1 \%$ prevalence estimate from faecal and cloacal swaps of in intensive poultry farms in Hawassa [32]. Comparable results were also reported in Egypt [33] and in Nepal [34]. By contrast, a higher prevalence in Jima (41.9\%) was recorded [35], and a lower prevalence (9.3\%) in East Showa, Ethiopia [26], was recorded. The differences in the prevalence estimates could be due to differences in environmental contamination, management systems, breed, sample size, and method of isolation.

Except two isolates, all were resistant to at least a single antimicrobial. A considerably higher proportion of the isolates $43(86.0 \%)$ was resistant to two or more of the antimicrobials, and 26 multidrug resistance profiles were observed. Multidrug resistant is considered when it is simultaneously resistant to two or more drugs [36]. The number of isolates resistant to five drugs was higher followed 
TABLe 1: Overall prevalence of Salmonella by sites of samples examined.

\begin{tabular}{lcccc}
\hline Farms & Number examined & Number positive (\%) & $\chi^{2}$ & df \\
\hline Alema & 133 & $28(21.1)$ & 7.083 & 2 \\
Aleka Amba & 131 & $16(12.2)$ & & \\
Modjo & 120 & $12(10.0)$ & & \\
Total & 384 & $56(14.6)$ & & \\
\hline
\end{tabular}

$\mathrm{df}=$ degree of freedom.

TABle 2: Prevalence of Salmonella in slaughtered chicken by risk factors.

\begin{tabular}{|c|c|c|c|c|c|c|}
\hline \multicolumn{2}{|c|}{ Risk factors } & \multirow{2}{*}{$\frac{\text { Number of samples }}{264}$} & \multirow{2}{*}{$\frac{\text { Prevalence (\%) }}{44(15.2)}$} & \multirow{2}{*}{$\frac{\chi^{2}}{2.94}$} & \multirow{2}{*}{$\frac{\mathrm{df}}{1}$} & \multirow{2}{*}{$\frac{p \text { value }}{0.086}$} \\
\hline & 1900 masl & & & & & \\
\hline Altitude & 1774 masl & 120 & $12(13.3)$ & & & \\
\hline \multirow{2}{*}{ Sex } & Female & 192 & $30(15.6)$ & 0.334 & 1 & 0.563 \\
\hline & Male & 192 & $26(13.5)$ & & & \\
\hline
\end{tabular}

masl = meter above sea level; $\mathrm{df}=$ degree of freedom.

TABLE 3: Number (\%) of Salmonella isolates resistant to antimicrobials.

\begin{tabular}{lccc}
\hline Antibiotics & Susceptible (\%) & Intermediate (\%) & Resistant (\%) \\
\hline AMC & $25(50.0)$ & $13(26.0)$ & $12(24.0)$ \\
AMP & $11(22.0)$ & $4(8.0)$ & $35(70.0)$ \\
CHL & $25(50)$ & $8(16.0)$ & $17(34.0)$ \\
CRO & $39(78.0)$ & $8(16.0)$ & $3(6.0)$ \\
KAN & $13(26.0)$ & $24(48.0)$ & $13(26.0)$ \\
NAL & $14(28.0)$ & $7(14.0)$ & $29(58.0)$ \\
OXT & $4(8.0)$ & $5(10.0)$ & $41(82.0)$ \\
STR & $19(36.0)$ & $16(32.0)$ & $15(30.0)$ \\
SXT & $16(32.0)$ & $6(12.0)$ & $28(56.0)$ \\
Total & $166(36.9)$ & $91(20.2)$ & $193(42.9)$ \\
\hline
\end{tabular}

TAвLE 4: Multiple antimicrobial resistance profiles of Salmonella isolates $(n=43)$.

\begin{tabular}{|c|c|c|}
\hline Number of antimicrobials & Resistance pattern (no of isolates) & Number of isolates (\%) \\
\hline Two & $\begin{array}{l}\text { AMP, OXT (3); AMP, AMC (1); AMC, KAN (1) } \\
\text { OXT, NAL (2); CHL, NAL (1); SXT, NAL (1) }\end{array}$ & $9(18)$ \\
\hline Three & AMP, AMC, OXT (4); AMC, OXT, SXT (3) & $7(14)$ \\
\hline Four & $\begin{array}{c}\text { AMP, AMC, OXT, KAN (1); AMP, AMC, OXT, SXT (1); } \\
\text { SXT, OXT, AMP, STR (1); SXT, OXT, AMP, NAL (1); } \\
\text { SXT, OXT, NAL, STR (1); OXT, CHL, NAL, AMP (2); } \\
\text { OXT, CHL, NAL, STR (1) }\end{array}$ & $8(16)$ \\
\hline Five & $\begin{array}{l}\text { AMP, AMC, OXT, SXT, NAL (1); AMP, AMC, OXT, CRO, STR (1) } \\
\text { AMP, OXT, CHL, SXT, NAL (2); AMP, OXT, SXT, NAL, KAN (2) } \\
\text { AMP, OXT, CHL, NAL, KAN (1); AMP, OXT, CHL, SXT, STR (1) } \\
\text { AMP, OXT, NAL, SXT, STR (2); OXT, CHL, SXT, NAL, KAN (1) }\end{array}$ & $11(22)$ \\
\hline Six & $\begin{array}{l}\text { OXT, AMP, CHL, NAL, SXT, STR (4); } \\
\text { OXT, AMP, CHL, NAL, SXT, KAN (3) }\end{array}$ & $7(14)$ \\
\hline Seven & OXT, AMP, CHL, NAL, SXT, KAN, STR (1) & $1(2)$ \\
\hline
\end{tabular}

by two drug-resistant isolates. Most of the antimicrobial drugs for which Salmonella isolates were resistant in this study were reported earlier from Ethiopia from different food animals, food products, and humans [37-40]. The types of antibiotic resistant for the isolates in this study are also in agreement with different reports in other parts of African [41] and European countries [42, 43].
In developing countries, antimicrobial resistance levels have markedly increased, and this could be due to the indiscriminate and widespread uses of antimicrobials both in the veterinary and public health practices as access to antimicrobials is easy and can be purchased without prescription [44-46]. Salmonella isolates resistant to the relatively cheaper and commonly available antimicrobials is disturbing as the 
resistance causes more expensive therapies and longer duration of sickness. The resistant pattern of Salmonella in poultry confers to drugs such as ceftriaxone that used for treating salmonellosis in humans. This suggests that chicken could be a source for multidrug-resistant salmonellosis in humans [47].

The present work contributes considerably towards understanding of the prevalence of Salmonella and the antibiotic resistance features of chicken isolates in Ethiopia. Serotyping of the isolates will complement this report and enable us understanding the serotypes.

\section{Conclusion and Recommendations}

The overall prevalence of Salmonella in chicken is considerable, and the antibiotic resistance feature of the subjected isolates is recorded high. Chicken are potential sources of foodborne salmonellosis and antimicrobial resistant Salmonella that pose a high risk to both animals and humans. Awareness should be created to avoid indiscriminate use of antimicrobials. There should be intense and effective communication between veterinary organizations and human health care providers to control spread of salmonellosis and to target antibiotic resistance. Further studies are needed to describe the occurrence of Salmonella in chicken and the risk factors that favor the emergence of drug-resistant isolates.

\section{Data Availability}

The data used to support the findings of this study are included within the article in the frequency table.

\section{Disclosure}

We declare that the information presented herein our work is original, and all sources of materials used for the research work have been duly acknowledged.

\section{Conflicts of Interest}

The authors declare that they have no conflicts of interest.

\section{Acknowledgments}

We are first grateful to the University. The commercial processing plants, the private holders, and the employees for their allowance and cooperation during the process of sampling are also thankful. We would also like to acknowledge Drs. Getachew Tadesse and Tesfaye Sisay for their inspiring intellectual and moral support throughout this research. The work incorporated in this research was undertaken using the research grant allocated by the Institute of Biotechnology, Addis Ababa University.

\section{References}

[1] S. S. Yan, M. Pendrak, B. Abela-Ridder, J. Punderson, D. Fedorko, and S. Foley, "An overview of Salmonella typing: public health perspectives," Clinical and Applied Immunology Reviews, vol. 4, no. 3, pp. 189-204, 2004.
[2] A. Stevens, Y. Kabore, J. Perriergrosclaude et al., "Prevalence and antibiotic-resistance of Salmonella isolated from beef sampled from the slaughterhouse and from retailers in Dakar (Senegal)," International Journal of Food Microbiology, vol. 110, no. 2, pp. 178-186, 2006.

[3] D. G. White, S. Zhao, R. Sudler et al., "The isolation of antibiotic-resistant Salmonella from retail ground meats," New England Journal of Medicine, vol. 345, no. 16, pp. 1147-1154, 2001.

[4] J. Ayers and H. Farah, "Chicken consumption continues long run rise," Amber Waves, vol. 4, p. 5, 2006.

[5] P. Quinn, M. Carter, B. Markey, and G. R. Carter, Clinical Veterinary Microbiology, Mosby, Maryland Heights, MO, USA, 2000.

[6] P. Grimont and F. Weill, Antigenic Formulae of the Salmonella Serovars, Institute of Pasteur and WHO, Paris, France, 2007, https://www.pasteur.fr/sante/clre/cadrecnr/salmoms-index.html.

[7] C. Wray and R. Davies, "The epidemiology and ecology of Salmonella in meat producing animals," in Microbial Food Safety in Animal Agriculture. Current Topics, M. E. Torrence and R. E. Isaacson, Eds., pp. 73-82, Blackwell Publishing, Hoboken, NJ, USA, 1st edition, 2003.

[8] I. Gantois, R. Ducatelle, F. Pasmans et al., "Mechanisms of egg contamination by Salmonella enteritidis," FEMS Microbiology Reviews, vol. 33, no. 4, pp. 718-738, 2009.

[9] N. Dana, L. H. van der Waaij, T. Dessie, and J. A. M. van Arendonk, "Production objectives and trait preferences of village poultry producers of Ethiopia: implications for designing breeding schemes utilizing indigenous chicken genetic resources," Tropical Animal Health and Production, vol. 42, no. 7, pp. 1519-1529, 2010.

[10] P. A. Barrow, M. A. Jones, A. L. Smith, and P. Wigley, "The long view:Salmonella- the last forty years," Avian Pathology, vol. 41, no. 5, pp. 413-420, 2012.

[11] WHO, "Drug resistant Salmonella," March 2014, http://www. who.int/mediacentre/factsheets/fs139/en/.

[12] L.-H. Su, C. Chu, A. Cloeckaert, and C.-H. Chiu, "An epidemic of plasmids? Dissemination of extended-spectrum cephalosporinases among Salmonella and other Enterobacteriaceae," FEMS Immunology \& Medical Microbiology, vol. 52, no. 2, pp. 155-168, 2008.

[13] A. García-Fernández, D. Fortini, K. Veldman, D. Mevius, and A. Carattoli, "Characterization of plasmids harbouring qnrs1, qnrb2 and qnrb19 genes in Salmonella," Journal of Antimicrobial and Chemotherpy, vol. 63, no. 2, pp. 274-281, 2009.

[14] W. Strohl, H. Rouse, and B. Fisher, Microbiologia Ilustrada, Artmed, Porto Alegre, Brazil, 2004.

[15] F. J. Angulo, K. R. Johnson, R. V. Tauxe, and M. L. Cohen, "Origins and consequences of antimicrobial-resistant nontyphoidal Salmonella: implications for the use of fluoroquinolones in food animals," Microbial Drug Resistance, vol. 6, no. 1, pp. 77-83, 2000.

[16] H. Murungkar, H. Rahman, A. Kumar, and D. Bhattacharya, "Isolation, phage typing and antibiogram of Salmonella from man and animals in Northeastern India," Indian Journal of Medical Research, vol. 122, no. 3, pp. 237-242, 2005.

[17] K. Aragaw, B. Molla, A. Muckle et al., "The characterization of Salmonella serovars isolated from apparently healthy slaughtered pigs at Addis Ababa abattoir, Ethiopia," Preventive Veterinary Medicine, vol. 82, no. 3-4, pp. 252-261, 2007.

[18] E. Zewdu and P. Cornelius, "Antimicrobial resistance pattern of Salmonella serotypes isolated from food items and personnel in Addis Ababa, Ethiopia," Tropical Animal Health and Production, vol. 41, no. 2, pp. 241-249, 2009. 
[19] M. Bahn, R. Bahl, and S. Bhatnagar, "Typhoid and paratyphoid fever," The Lancet, vol. 366, no. 9487, pp. 749-762, 2005.

[20] WHO, "Food safety and food borne illness," 2014, http:// www.who.int/mediacentre/factsheets/fs237/edu.

[21] T. Getachew, "Prevalence of human Salmonellosis in Ethiopia: a systematic review and meta-analysis," Biomedical Science Infectious Diseases, vol. 14, no. 1, p. 88, 2014.

[22] A. Animut, Y. Mekonnen, D. Shimelis, and E. Ephraim, "Febrile illnesses of different etiology among outpatients in four health centers in Northwestern Ethiopia," Japan Journal of Infectious Diseases, vol. 62, no. 2, pp. 107-110, 2009.

[23] USDA, "Food-borne illness cost calculator: Salmonella data set," 2014, http://www.ers.usda.gov/data/foodborneillness/ salm_Intro.asp.

[24] C. G. Scanes, "Poultry science: celebrating its impact factor, impact, and quality," Poultry Science, vol. 86, no. 1, p. 1, 2007.

[25] B. Afera, F. Regassa, and A. Issa, "Seroprevalence of fowl typhoid in selected areas east of Shewa, Ethiopia," Veterinarian Organizations Revision, vol. 13, pp. 1-13, 2012.

[26] M. Endris, F. Taddesse, M. Geloye, T. Degefa, and T. Jibat, "Sero and media culture prevalence of Salmonellosis in local and exotic chicken, Debre Zeit, Ethiopia," African Journal of Microbiology Research, vol. 7, pp. 1041-1044, 2013.

[27] CSA, "Agricultural sample survey 2009/10. Report on livestock and livestock characteristics," in Statistical Bulletin No. 468, CSA, Addis Ababa, Ethiopia, 2009.

[28] M. Thrusfield, Veterinary Epidemiology, Black well Science Limited, Cambridge, UK, 3rd edition, 2007.

[29] ISO, Detection of Salmonella spp. in Animal Faeces and in Samples of the Primary Production Stage Horizontal Method for the Detection of Salmonella spp., International Organization for Standardization, Geneva, Switzerland, 2002.

[30] GSS and WHO, A Global Salmonella Surveillance and Laboratory Support Project of the WHO, Laboratory Protocols Level 1 Training Course Identification of Salmonella, R. S. Hendriksen, Ed., WHO, Geneva, Switzerland, 4th edition, 2003.

[31] CLSI, Performance Standards for Antimicrobial Susceptibility Testing. Twenty-Second Informational Supplement, Approved Standard CLSI Document M100-S23 (M02-A11), Wayne, PA, USA, 2012.

[32] A. Kassaye, T. Lencho, and A. Mesele, "Prevalence of Salmonella infection in intensive poultry farms in hawassa and isolation of Salmonella species from sick and dead chickens," Ethiopian Veterinary Journal, vol. 14, no. 2, pp. 115-124, 2011.

[33] M. Ibrahim, H. Emeash, N. Ghoneim, and M. Abdel-Halim, "Seroepidemiological studies on poultry salmonellosis and its public health importance," Journal of World's Poultry Research, vol. 3, no. 1, pp. 18-23, 2013.

[34] A. Maripandi and A. A. Al-Salamah, "Multiple-antibiotic resistance and plasmid profiles of Salmonella enteritidis isolated from retail chicken meats," American Journal of Food Technology, vol. 5, no. 4, pp. 260-268, 2010.

[35] K. Alebachew and A. Mekonnen, "A survey on Salmonella infection among chicken flocks in Jimma town, Ethiopia," African Journal of Microbiology Research, vol. 7, no. 14, pp. 1239-1245, 2013.

[36] W. Tavares, Manual of Antibiotics and Chemotherapeutics of Infections, Ateneu Santista, Sao Paulo, Brazil, 3rd edition, 2001.

[37] D. Alemayehu, B. Molla, and A. Muckle, "Prevalence and antimicrobial resistance pattern of Salmonella isolates from apparently healthy slaughtered cattle in Ethiopia," Tropical
Animal Health and Production, vol. 35, no. 4, pp. 309-319, 2003.

[38] B. Molla, A. Mesfin, and D. Alemayehu, "Multiple antimicrobial resistant Salmonella serotypes isolated from chicken carcases and giblets in Debre Zeit and Addis Ababa, Ethiopia," Ethiopian Journal of Health Development, vol. 17, pp. 131-149, 2003.

[39] Z. Endrias, Prevalence, Distribution and Antimicrobial Resistance Profile of Salmonella Isolated from Food Items and Personnel in Addis Ababa, Ethiopia, MSc thesis, Faculty of Veterinary Medicine, Addis Ababa University, Addis Ababa, Ethiopia, 2004.

[40] Z. Addis, N. Kebed, and Z. Worku, "Prevalence and antimicrobial resistance of Salmonella isolated from lactating cows and in contact humans in dairy farms of Addis Ababa," Biomedical Science Infectious Diseases, vol. 11, no. 1, pp. 222-228, 2011.

[41] SANVAD, "South african national veterinary surveillance and monitoring programme for resistance to antimicrobial drugs," The South African Medical Journal, vol. 101, p. 8, 2007.

[42] R. O’Mahony, T. Quinn, D. Drudy et al., “Antimicrobial resistance in nontyphoidal Salmonella from food sources in Colombia: evidence for an unusual plasmid-localized class 1 integron in serotypes typhimurium and anatum," Microbial Drug Resistance, vol. 12, no. 4, pp. 269-277, 2006.

[43] WHO, "Antibiotic resistance," 2014, http://www.who.int/. Narrated.in.

[44] J. Picard, "Veterinary surveillance of antimicrobial resistance in South Africa," in Proceedings of the Presentation at The Global Antibiotic Resistance Partnership Inaugural Meeting, vol. 8-9, Stellenbosch, South Africa, February 2010.

[45] M. Henton, H. Eagar, G. Swan, and M. van Vuuren, "Antibiotic management and resistance in livestock production," The South African Medical Journal, vol. 101, p. 8, 2011.

[46] OIE, "The OIE Regional Commission for Africa," in Proceedings of the 14th Conference of the OIE, Tehran, Iran, November 2011.

[47] N. M. M'ikanatha, C. H. Sandt, A. R. Localio et al., "Multidrug-resistant Salmonella isolates from retail chicken meat compared with human clinical isolates," Foodborne Pathogens and Disease, vol. 7, no. 8, pp. 929-934, 2010. 